\title{
Varicella pneumonia in an immunocompromised adult: Not always fatal!
}

\section{Selma El Kadiri, Zakia Douhi, Soukaina Chhiti, Rhizlane Chaoui, Sara Elloudi, Hanane Baybay, Fatima-Zahra Mernissi}

\author{
Department of Dermatology, Hassan II Universitary Hospital, Fez, Morocco
}

Corresponding author: Dr. Selma El Kadiri, E-mail: elkadiri-s@hotmail.com

\begin{abstract}
Chickenpox is a very common and usually mild rash disease in healthy children. In adults especially immunocompromised, its course may be punctuated by serious complications such as varicella pneumonia. Herein we report a case of a 48 -yearold male patient followed for stage IV Hodgkin lymphoma treated by the BEACOPPR protocol and referred for severe pneumonia varicella. Radiologic exploration showed multiple bilateral micronodular and reticulonodular opacities, diffuse throughout the lungs. Laboratory exams revealed g severe hypoxemia and pancytopenia. The patient received antiviral treatment acyclovir ( $10 \mathrm{mg} / \mathrm{kg} / 8$ hours) intravenously, combined with oxygen therapy via nasal cannula on 5 $\mathrm{L} / \mathrm{min}$ and prednisone $60 \mathrm{mg}$ per day for 5 days with favorable evolution.
\end{abstract}

Key words: Varicella pneumonia; Immunocompromised adult; Treatment

\section{INTRODUCTION}

Chickenpox is a very common and usually mild rash disease in healthy children. In adults especially immunocompromised, its course may be punctuated by serious complications such as varicella pneumonia [1]. Herein we report a case of pneumonia varicella with Hodgkin lymphoma under chemotherapy.

\section{CASE REPORT}

A 48-year-old male patient followed for stage IV Hodgkin lymphoma treated by the BEACOPPR protocol presented to our department for cough, fever, dyspnea, generalized necrotic vesicular rash, and malaise evolving 5 days before. Vital signs demonstrated tachycardia (109bpm), temperature $39^{\circ}$, and SpC2 of $82 \%$ on room air. Physical examination showed diffuse maculopapular to vesicular lesions with an erythematous halo with crusting (Fig. 1). He didn't reveal a previous chickenpox history. Chest radiography demonstrated multiple bilateral micronodular and reticulonodular opacities, diffuse throughout the lungs. It also revealed left pleural effusion related to his Hodgkin lymphoma (Fig. 2). CT scan revealed the existence of multiple well and ill-defined nodules, diffusely dispersed throughout both lungs. Therefore, we diagnosed with varicella pneumonia. Laboratory exams showed on arterial gasometry severe hypoxemia $(\mathrm{PaO} 2=45 \mathrm{mmHg}, \mathrm{pH}=7.48, \mathrm{SaO} 2=82 \%)$, leucopenia at $52 / \mathrm{mm}^{3}$, lymphopenia at $220 / \mathrm{mm} 3$, thrombocytopenia at $13,000 / \mathrm{mm}$, moderate hepatic cytolysis (ALT $180 \mathrm{IU} / \mathrm{l}$ ), a CRP at $125 \mathrm{mg} / 1$, an elevation of lacticodehydrogenases (LDH) to $1205 \mathrm{IU} / 1$, hypoalbuminemia at $24 \mathrm{~g} / 1$. The patient received antiviral treatment acyclovir $(10 \mathrm{mg} / \mathrm{kg} / 8$ hours $)$ intravenously, combined with oxygen therapy via nasal cannula on $5 \mathrm{~L} / \mathrm{min}$ and prednisone $60 \mathrm{mg}$ per day for 5 days. The evolution was favorable with obtaining apyrexia after 4days of treatment, improvement of dyspnea with correction of hypoxemia on the eighth day of treatment (Figs. 3a, 3b and 4). The patient followed his chemotherapy 15 days after recovery. 


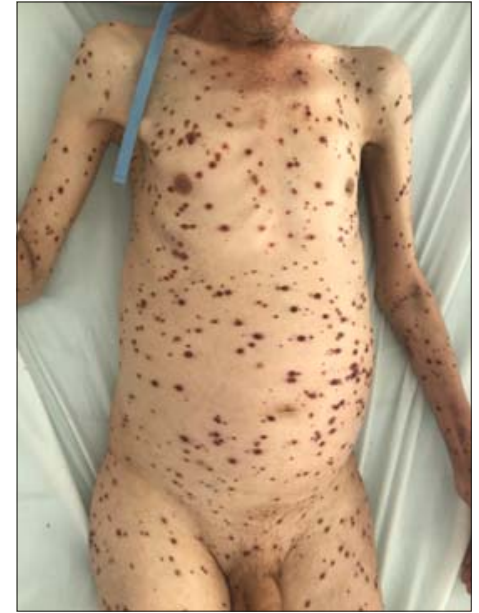

Figure 1: Maculopapular to vesicular lesions with an erythematous halo with crusting.

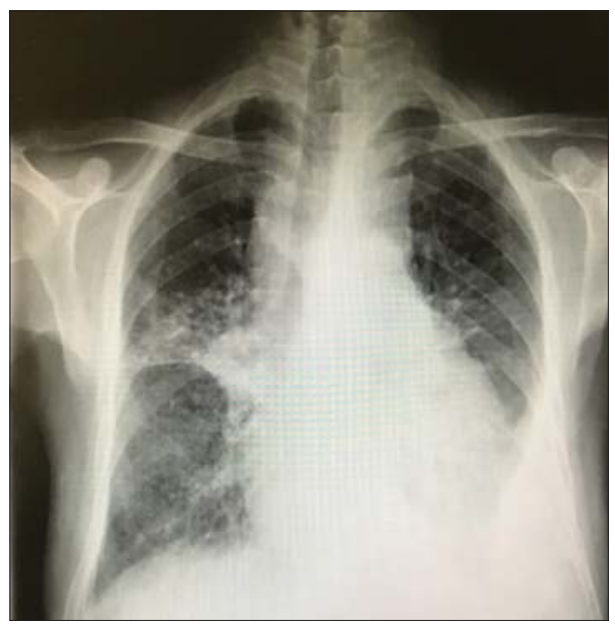

Figure 2: Bilateral micronodular and reticulonodular opacities, diffuse throughout the lungs.

\section{DISCUSSION}

Chickenpox is a highly contagious infection caused by the VZV, commonly diagnosed in childhood, but with increasing prevalence in adults [1]. More than $90 \%$ of adult cases of varicella pneumonia occur in patients with lymphoma or other immunocompromising conditions. The risk factors for acute lung injury due to varicella infection are as follows: male sex, adult, smoking, greater than 100 skin lesions, pregnancy, close contact with an infected person, or any immunosuppression [2]. Our patient had several of these risk factors (adult, male sex, immunodepression); moreover, he was not previously exposed to chickenpox in childhood.

Pneumonia is usually self-limiting, and recovery is temporally correlated with the clearing of skin lesions [3]. Blood gas analyses and pulmonary function

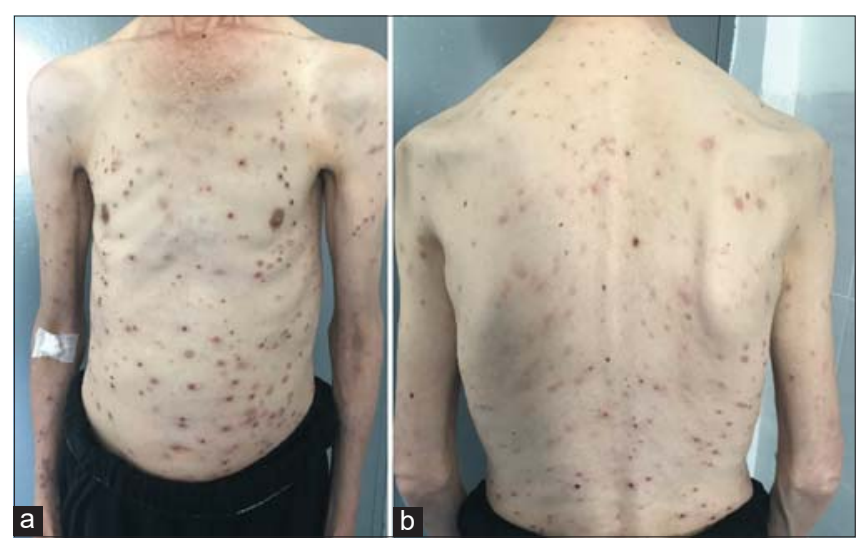

Figure 3: $(a$ and $b)$ control at 10 days after starting antiviral treatment.

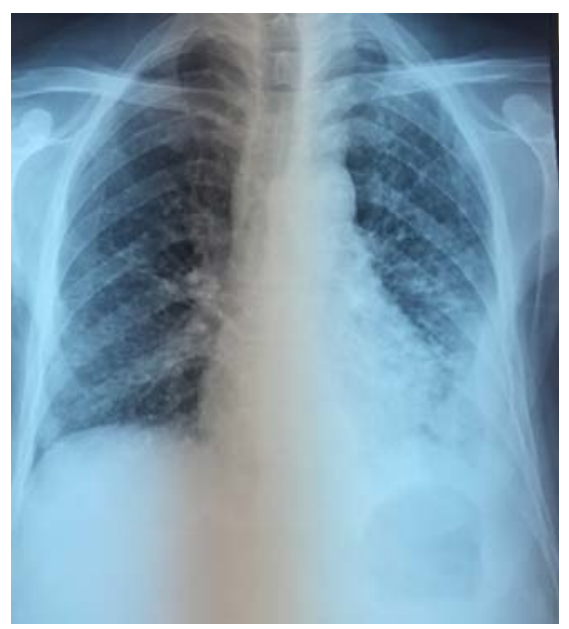

Figure 4: Incomplete radiological cleaning.

tests indicate a significant diffusion defect that may persist in some cases for months after clinical recovery. The radiological characteristics consist of multiple bilateral 5-10 mm, ill-defined nodules, which may be confluent. Occasionally, hilar lymphadenopathy, reticular opacities, and pleural effusions may occur [4]. In our patient, acute respiratory failure occurred 3 days after the onset of the disease with significant radiologic changes. The outcome was favorable in this case. Acyclovir, Vidarabine, and interferon have been used for the treatment of cutaneous and visceral varicella in immunocompromised patients but little is known about their efficacy in varicella pneumonia [1]. The use of corticosteroids in severe forms has not been studied with sufficient evidence [2]. One patient was treated also by corticosteroids which have been known to reduce the duration of hospitalization.

\section{CONCLUSION}

Varicella pneumonia is a serious and severe complication of the disease when it occurs in adults. Early antiviral 
www.odermatol.com

treatment with acyclovir is recommended in the case of varicella pneumonia proven and can reduce the risk of mortality.

\section{Consent}

The examination of the patient was conducted according to the Declaration of Helsinki principles.

The authors certify that they have obtained all appropriate patient consent forms. In the form the patient(s) has/have given his/her/their consent for his/her/their images and other clinical information to be reported in the journal. The patients understand that their names and initials will not be published and due efforts will be made to conceal their identity, but anonymity cannot be guaranteed.

\section{REFERENCES}

1. Dah Cherif A, Elloudi S, Chaouche M, Barbach Y, Baybay H, Mernissi FZ. Varicella pneumonia: A serious complication of varicella in adults]. Our Dermatol Online. 2019;10:e21.1-e21.4.

2. Ljungman P. Varicella zoster virus vaccine in patients with haematological malignancies. Lancet Infect Dis. 2019;19:921-2.

3. D. Mangioni, Giacomo Grasselli. Adjuvant treatment of severe varicella pneumonia with intravenous varicella zoster virus-specific immunoglobulins. Int J Infect Dis. 2019;85:70-3.

4. Malherbe J, Iachkine J, du Cheyron D, Valette X. Diffuse Varicella Zoster Virus reactivation in critically III immunocompromised patient. Intensive Care Med. 2020;46:381-2.

Copyright by Selma El Kadiri, et al. This is an open-access article distributed under the terms of the Creative Commons Attribution License, which permits unrestricted use, distribution, and reproduction in any medium, provided the original author and source are credited.

Source of Support: Nil, Conflict of Interest: None declared. 